\title{
Al-Durūs al-Hasaniyya: el discurso institucional islámico y la legitimación de la monarquía marroquí
}

Al-Durūs al-Hasaniyya: Islamic institutional discourse and the legitimization of the Moroccan monarchy

Miguel A. FERNÁNDEZ-FERNÁNDEZ

Universidad de Granada

miguelfernandez@ugr.es

https://orcid.org/0000-0003-0700-6061

Recibido 22/10/2020. Aceptado 15/05/2021

Para citar este artículo: Miguel A. FERNÁNDEZ-FERNÁNDEZ (2021):" Al-Durūs al-Ḥasaniyya: el discurso institucional islámico y la legitimación de la monarquía marroquí" en Revista de Estudios Internacionales Mediterráneos, 30, pp. 82-95.

Para acceder a este artículo: https://doi.org/10.15366/reim2021.30.005

\section{Resumen:}

La monarquía marroquí, como élite en competición por un recurso limitado (la hegemonía del discurso islámico marroquí), utiliza los instrumentos discursivos y semiológicos a los que tiene acceso de manera exclusiva con el objetivo de mantener sus privilegios. En este artículo se pretende estudiar cómo la institución monárquica marroquí utiliza para este propósito los al-Durūs alHasaniyya (Lecciones Hasaníes), un ciclo de conferencias o lecciones de temática islámica que acontece bajo la presencia del rey de Marruecos en calidad de Amir al-Mu'minin durante el mes islámico de Ramadán.

Palabras clave: al-Durūs al-Ḥasaniyya/ discurso islámico/ Marruecos/ monarquía/ legitimidad/

\section{Abstract:}

The Moroccan monarchy, as an elite in competition for a limited resource (the hegemony of Moroccan Islamic discourse), uses the discursive and semiological instruments to which it has access 
exclusively in order to maintain its privileges. In this light, the aim of this paper is to study how the Moroccan monarchical institution uses the al-Durūs al-Hasaniyya (Hasani Lectures), a cycle of lectures about Islamic topics that takes place under the presence of the King of Morocco as Amir al-Mu'minin during the Islamic month of Ramadan.

Keywords: al-Durūs al-Hasaniyya/ Islamic discourse/ Morocco/ Monarchy/Legitimacy/

\section{Introducción: la hegemonía del discurso religioso}

La institución monárquica marroquí es una de las piezas fundamentales de las estructuras de poder que rigen el funcionamiento de este país. Tal y como señalan autores como J. A. Macías Amoretti (Macías Amoretti, 2008: 69-70) o M. A. Martínez Núñez (Martínez Núñez, 2006: 177-179), así como algunos de los clásicos de la sociología marroquí como M. Tozy (Tozy: 2000, 74-79), la monarquía alauí hunde sus bases en la reinterpretación de las instituciones clásicas y en la relectura del pasado islámico. El presente trabajo coloca su foco de manera exclusiva en la utilización del discurso islámico por parte de la institución monárquica siguiendo la estela de los trabajos de L. Fernández Fonfría (Fernández Fonfría, 2018), M. El-Katiri (El-Katiri, 2015) o M. Pérez Mateo (Pérez Mateo, 2015). Por ello, el objetivo del presente artículo es ilustrar, a través de un análisis pormenorizado del ceremonial de las al-Durūs al-Hasaniyya (Lecciones Hasaníes), la siguiente idea de M. A. Martínez Núñez referente al Marruecos contemporáneo.

"En el caso de la monarquía 'alawí, se trata de una utilización de la tradición - el šarīfismo, la imitación del Profeta, la dignidad califal - para fines concretos, para otorgar una cobertura religiosa a la relación nueva que existe, o debe existir, entre el jefe de Estado y los ciudadanos de un Estado que se rige ahora por leyes ajenas a la šarī'a; una cobertura religiosa que consolida, por encima del nuevo ordenamiento, los privilegios del soberano" (Martínez Núñez, 2006: 178).

La elección como objeto de estudio de este ciclo de conferencias presididas por el monarca marroquí en calidad de Amīr al-Mu'minīn ${ }^{1}$ reside en su riqueza discursiva y semiológica. Este trabajo considera las Lecciones Hasaníes en sí como un recurso legitimador al servicio de la monarquía al igual que otros ceremoniales como la bay'a (juramento de lealtad al monarca). Para ello, se ha partido del marco teórico propuesto por por F. Izquierdo Brichs y T. A. Van Dijk en torno a la Sociología del Poder y al Análisis Crítico del Discurso (ACD) respectivamente. Por otro lado, este trabajo se introduce en cierto modo en el ámbito de la semiótica al analizar un contexto comunicativo con un alto grado de significación.

El presente artículo parte de la premisa de que en la sociedad marroquí el islam es un marco de referencia en torno al cual existe un consenso generalizado que penetra multitud de aspectos de la vida de los habitantes de este país, lo que permite una reinterpretación del folclore y los símbolos de una manera favorable para ejercer y mantener la autoridad política (Daadaoui, 2011: 72). El papel determinante que ocupa el discurso religioso en la estructura de poder estudiada, como explica F. Izquierdo Brichs mediante el concepto gramsciano de "hegemonía cultural", se debe a que el islam es considerado como un sistema de creencias universalizado que hace que el interés de un grupo concreto pueda ser aceptado como beneficioso para el conjunto de las sociedad (Izquierdo Brichs, 2009: 51).

\footnotetext{
${ }^{1}$ Bien es cierto la existencia en español del término miramamolín, no obstante en este artículo se ha preferido utilizar la transcripción del término en árabe. Para el título de Amīr al-Múminīn, véase GIIB, H. A. R. :1979, 446.
} 
Siguiendo la hipótesis planteada por M. A. Martínez Núñez, el último fin de la utilización de la tradición (el šarīfismo, la imitación del Profeta o la dignidad califal) por parte de la monarquía es mantener ciertos privilegios, lo que unido a la siguiente afirmación de F. Izquierdo Brichs permite definir la institución monárquica marroquí como una élite en competición: "consideramos pues élites a los individuos que se encuentran en una posición jerárquica superior en las instituciones sociales y cuya supervivencia en esta posición depende de su capacidad para competir por la acumulación de poder" (Izquierdo Brichs, 2009: 25). Por tanto, el interés último de la monarquía en este ámbito sería mejorar su posición respecto a las demás élites que compiten por el mismo recurso. En este caso concreto, la hegemonía del discurso religioso marroquí. Por consiguiente, la institución monárquica, para preservar sus privilegios derivados de la legitimidad que le otorga la tradición islámica marroquí, ha de acumular un caudal de legitimidad religiosa mayor que el de sus competidores directos.

La monarquía marroquí a lo largo de la historia ha encontrado en el discurso religioso un caudal legitimador que siempre ha usado. Un ejemplo sería cómo en el proceso de independencia utilizó este recurso para desactivar a posibles competidores y hacerse con el liderazgo del relato nacionalista. Por ejemplo, en los años 70 la monarquía llegó a promover movimientos islamistas como al-Šabība al-Islāmīya (Juventud Islámica) con el objetivo frenar la expansión del naserismo y la influencia de la izquierda marxista en las universidades (Casani, 2017). En época más reciente y en un contexto nacional diferente al anterior, la institución monárquica ha continuado utilizando y modelando el discurso islámico estatal con fines legitimadores, bien para moldear movimientos islamistas como el del partido PJD (Macías Amoretti, 2017) o para hacer frente a movimientos como Justicia y Espiritualidad que no aceptan el orden constitucional monárquico (Casani, 2017).

Como explica T. A. Van Dijk, las relaciones de poder en último término son discursivas: "los grupos hegemónicos son los que controlan el texto, el contexto $y$, en consecuencia, las mentes de las personas" (Van Dijk, 2003: 205). De modo que el ACD, permite entender el alcance de las Lecciones Hasaníes como instrumento de poder al servicio de la monarquía al aportar la aproximación necesaria para realizar un análisis pormenorizado del acto discursivo en sí y del contexto que las envuelve.

Por ello, el presente artículo pretende analizar desde esta óptica discursiva y semiológica, no los discursos propios de las lecciones, sino el acceso privilegiado que la institución monárquica tiene respecto a la utilización de los recursos simbólicos (el paradigma de la Imārat al-Mu'minīn), la disposición de la situación comunicativa (el control del lugar y el tiempo en el que transcurren estas lecciones), el desarrollo de las acciones en curso (el ceremonial) y el control de los participantes (aquellos actores implicados en el acto discursivo) (Van Dijk, 2003: 208-209). Por lo que respecta a la semiótica, este artículo pretende analizar el sistema de signos que se genera en torno a las Lecciones Hasaníes como proceso comunicativo que requiera una respuesta interpretativa por parte del destinatario y en el que es indispensable la existencia de un código. En este caso concreto, un código creado en torno a la tradición y a la religión islámica (Eco, 2000: 24-25).

Este estudio se ha realizado a partir del análisis de las Lecciones Hasaníes disponibles en línea a través de las cuentas oficiales del Ministerio de Habous y Asuntos Islámicos², así como la consulta de las lecciones editadas y publicadas por este ministerio. El objetivo de este artículo no es abarcar la temática concreta de este ciclo de lecciones, sino analizar el ceremonial y sus implicaciones

2 Página oficial de las Lecciones Hasaníes del Ministerio de Habous y Asuntos Islámicos http://www.habous.gov.ma/tv/2017/5847-2015-07-20-09-13-64.html [consulta: 10 de junio de 2020]. 
discursivas en la legitimación de la institución monárquica ${ }^{3}$. Por ello, las lecciones que han sido analizadas no han sido escogidas por su contenido, sino por reflejar los elementos discursivos y semióticos que han sido considerados pertinentes para este análisis. Más concretamente, para conocer el ceremonial de la época más reciente se ha intentado analizar el material audiovisual de las lecciones disponibles de los últimos años (2019, 2018 y 2017), mientras que para analizar las de época anterior se han seleccionado aquellas lecciones en las que pueden apreciarse particularidades propias de ese periodo. También han resultado de gran utilidad dos obras publicadas por la misma institución en las que se recoge de manera detallada información sobre las Lecciones Hasaníes : al-Maŷālis al-'ilmiyya al-șultāniyya 'alà 'ahd al-dawla al-'alawiyya al-šarîfa (Los consejos científicos sultánicos en el reinado 'Alawī Šarīfí) (al-Ḥāšimī al-Balgītīi, 1996) y Dawr al-waqf fï l-ḥayāt al-taqāfiyya bi-l-magrib fí 'ahd al-dawla al- 'alawiyya (El papel del Waqf en la vida cultural marroquí durante el reinado 'Alawī Šarīfí) (Bū Rakba, 1996).

\section{1. ¿Qué son los al-Durūs al-Hasaniyya?}

Las Lecciones Hasaníes pueden definirse como el ciclo de conferencias o lecciones (dars en singular, durūs en plural) que acontece bajo la presencia del rey de Marruecos en calidad de Amìr al-Mu'minīn durante el mes islámico de Ramadán y ante la asistencia de representantes públicos marroquíes, así como invitados de otros países ${ }^{4}$. En ellas, eruditos o ulemas ('ulamā') de todo el mundo imparten, en un registro muy cuidado de la lengua árabe, una lección a partir de una aleya coránica o un hadiz del Profeta con intención de aportar una reflexión acerca de cuestiones de interés general y relativa actualidad desde los instrumentos teóricos propios de la jurisprudencia islámica (al-Ḥā̌simī al-Balgītīi, 1996: 166-167).

Esta asamblea anual, que inició Hasán II en el año 1963 (al-Ḥāšimī al-Balgītīi, 1996: 163), se ha mantenido hasta hoy día por el rey Mohamed VI. Los comienzos de este acto oficial deben enmarcarse en el contexto político marroquí de la década de los años 60. Como indican L. Fernández Fonfría (Fernández Fonfría, 2018: 732) y B. Tomé Alonso (Tomé Alonso: 2009, 191), en los años posteriores a 1960 la monarquía marroquí optó por apostar por el caudal de legitimidad religiosa ante el avance de los partidos de izquierda tradicionalmente laicos y el avance de movimientos islamitas como Justicia y Espiritualidad.

Estas lecciones, de acuerdo a la obra de Ā. al-Ḥāšimī al-Balgīțī (al-Hāǎšimī al-Balgīțī, 1996), deben encuadrarse en torno a lo que en la cultura islámica se conoce como maŷlis y, más concretamente, un maŷlis 'ilmī. El término maŷlis puede ser traducido como consejo, asamblea o reunión. Así lo refleja el propio título de la obra de la autora antes mencionada: Los consejos científicos sultánicos en el reinado 'Alawi Šarīfí. Finalmente, el adjetivo 'ilmī (científico) hace referencia a que los ulemas que participan en este ciclo de conferencias emplean los métodos y las fuentes de la jurisprudencia islámica para la elaboración discursiva de su lección.

\footnotetext{
${ }^{3}$ Los temas tratados en las Lecciones Hasaníes a lo largo de su historia son muy variados. No obstante, para entender las estrategias de legitimación de la monarquía resultan especialmente interesantes las lecciones impartidas cada año por los ministros de Habous y Asuntos Religiosos. El actual ministro, Aḥmed al-Tawfíq en sus lecciones ha tratado temas clave sobre los que se basa la estrategia legitimadora de la monarquía: el Emirato de los Creyentes, la adscripción de Marruecos a la doctrina jurídica malikí, el sufismo y la adhesión de Marruecos a la teología aš‘arí (al-aš́arīya). Esto cuatro aspectos, han sido definido por el propio ministro como las cuatro constantes religiosas del reino de Marruecos (al-țawābit al-dinīya)

${ }^{4}$ Se ha optado por el término lección para traducir al español dars, y no otros como conferencia, al considerarse que este refleja mejor el carácter didáctico que entraña el término en árabe.
} 


\section{Recursos simbólicos: la Imārat al-Mu'minin}

El eje en torno al cual gira todo el ceremonial de las Lecciones Hasaníes es la presidencia del rey de estas en calidad de Amīr al-Mu'minīn ${ }^{5}$. En cualquier caso, como indica M. Daadaoui la institución monárquica puede entenderse como la actualización del majzén clásico al concentrar actualmente en la institución monárquica el poder militar, la burocracia, la tutela del cuerpo oficial de ulemas y el liderazgo simbólico de las diferentes țarīqas sufíes del país (Daadaoui, 2011: 42). Siguiendo las ideas del ACD, este hecho comporta un claro ejemplo de "acceso privilegiado a un recurso social escaso" (Van Dijk, 2003: 207) al ser esta consideración, la de Amīr al-Mu'minīn, exclusiva para el monarca marroquí. Como se señalaba en la introducción, la legitimidad religiosa en Marruecos es un pilar fundamental para las estructuras de poder y, más concretamente, para la institución monárquica. Esta, como élite en competición, ha de mantener la hegemonía del discurso religioso para mantener sus privilegios. Este juego de poder basado en el discurso religioso encuentra su razón de ser en un paradigma clásico del islam: la Imārat al-Mu'minīn. Una figura recogida en la Constitución de 2011:

“El Rey, Amīr al-Mu'minin, vela por el respeto al islam. Es garante del libre ejercicio de culto.
El rey, Amìr al-Mu'minin, preside el Consejo Superior de Ulemas, encargado del estudio de
las cuestiones a las que se le someta. El Consejo es considerado la única instancia habilitada
para emitir fetuas (dictámenes religiosos) reconocidas oficialmente sobre las cuestiones que
se le planteen y ello de acuerdo a los principios y disposiciones de la religión islámica y sus
magnánimas metas. Las atribuciones, composición y modalidades de este Consejo serán
fijadas por dahír. El Rey ejerce las prerrogativas religiosas referentes a la Imārat al-Mu'minin
que le son autorizadas de manera exclusiva por requerimiento de este artículo a través de
los dahíres”6.

Según la tradición sunní, los orígenes del título de Amìr al-Mu'minin se remontan a la época de Muḥammad. Más concretamente, a la época del segundo califa rašĩūn, 'Umar ibn al-Jațțāb (634644 d.C.), quien lo utilizó por primera vez. A lo largo de la historia de la civilización islámica, esta dignidad ha sido empleada como título protocolario del califa. Esto no quiere decir que solo haya sido utilizado por gobernantes que hayan ostentado tal consideración, como es el caso de los omeyas o los abasíes, sino también por otras dinastías que no gozaban de tal consideración entre el islam sunní (Gibb: 1979: 445). Por lo que respecta al caso particular marroquí, esta afirmación de M. Tozy ayuda a comprender el marco mental en el que puede situarse el paradigma de la Imārat al-Mu'minin entre la sociedad marroquí:

"El reconocimiento de la autoridad del califa, la sumisión a todas las expresiones de dicha autoridad, se convierte en un hecho religioso. La obediencia al califa es una prueba de adhesión al islam, un acto de profesión musulmana" (Tozy: 2000, 28). La tarea de diferenciar entre el título de califa y el de Amìr al-Mu'minin es complicada y, en cualquier caso, no es el

\footnotetext{
${ }^{5}$ Este título podría ser traducido como comendador de los creyentes o emir de los creyentes. En cualquier caso, amīr se emplea para designar a aquellas personas que ostentan algún tipo de mando de gobierno, especialmente militar. Por otro lado, el término mu'minin (en genitivo plural) se traduce inequívocamente por creyentes.

6 "al-Dustūr" (La Constitución), al-Bawaaba al-Wațaniyya, disponible en: https://www.maroc.ma/ar/content/الدستور/a [consulta: 10 de junio de 2020].
} 
objetivo de este trabajo. Lo importante para este estudio es la consideración de "nobleza" islámica de la que gozan los monarcas marroquíes y que se recoge en los textos constitucionales desde 1962 (El-Katiri, 2014: 55). M. Hernando de Larramendi resuelve eficazmente la problemática en torno al título de Amìr al-Mu'minīn antes planteada de la siguiente manera: "Este título está sustentado en la condición de jerifes de los miembros de la dinastía alauí. Descendientes directos del profeta Muhammad, disfrutan de la baraka o bendición divina que los acompaña en el ejercicio de su soberanía como Malik (Rey) como principal Imam (encargado de guiar a la comunidad de creyentes)" (Hernando de Larramendi, 2017: 87).

\section{Disposición de la situación comunicativa: Las tardes de Ramadán}

Como explica T. A. Van Dijk, "El control de la situación comunicativa involucra el control sobre una o más categorías mencionadas-por ejemplo, decidir el tiempo y el lugar de un evento comunicativo o qué participantes deben estar presentes, en qué roles o identidades, o qué conocimientos $u$ opiniones deberían (o no) tener, y qué acciones sociales pueden o deben ser logradas en el discurso" (Van Dijk, 2003: 209). Por tanto, la disposición física y temporal de las Lecciones Hasaníes son un privilegio al alcance exclusivo de la monarquía que le permite explotar un recurso de legitimación básico para mantener la hegemonía del discurso religioso en Marruecos.

Este ciclo de conferencias se celebra durante las tardes de Ramadán, antes de la ruptura del ayuno y en lugares significativos - el palacio real de Rabat, el palacio real de Casablanca, el Mausoleo de Mohamed V en Rabat o la Mezquita de Hasán II en Casablanca. La celebración de este ciclo de lecciones en el mes sagrado de Ramadán, junto al paradigma de la Imārat al-Mu'minīn antes explicado, conforman uno de los recursos discursivos más potentes del ceremonial estudiado. Al fin y al cabo, la dignidad califa de Amìr al-Mu'minin implica el máximo reconocimiento religioso entre los musulmanes sunníes, lo que unido a la celebración de este ciclo de conferencias en el mes islámico más sagrado para los musulmanes, coloca a la institución monárquica en un plano atemporal que sobrepasa la realidad nacional marroquí.

Las lecciones se celebran poco después de la oración ritual del 'așr y antes de la llamada a la oración del magrib, oración que marca la ruptura del ayuno (al-Ḥāšimī al-Balgītī, 1996: 164). Es decir, un momento cuidadosamente seleccionado para llegar a una amplia audiencia televisiva reunida en sus casas a la espera de la hora de ruptura del ayuno ritual de Ramadán. La propia obra publicada por el ministerio en 1996 recoge la siguiente afirmación: "Estas lecciones son consideradas la perla que adorna la frente de la hermosa Marruecos, que gracias a ellas - las lecciones - se convierte en el foco de atención del mundo, que las sigue con interés y con gran admiración y que se convierte en la qibla - dirección a la que los fieles orientan sus oraciones- de los ulemas musulmanes" (alḤāšimī al-Balgītīi, 1996: 158).

\section{Acciones en curso: el ceremonial de un maŷlis}

Este epígrafe pretende, mediante el análisis de las constantes generales del ceremonial de las Lecciones Hasaníes, describir la manera en la que se relacionan en este acto discursivo los diferentes actores participantes $y$, de esta manera, entender el acceso privilegiado de la institución monárquica a esta forma específica de discurso. 
La duración de las lecciones ha variado a lo largo del tiempo. Como explica al-Hāšimī al-Balgịtī en su obra de 1996 (al-Ḥâšimī al-Balgītīi, 1996: 64), el ceremonial completo de las lecciones solía desarrollarse en unos en 45-60 minutos, mientras que en la época actual raramente parece superar la media hora ${ }^{7}$. Respecto al número de lecciones que se celebran cada año, este es poco homogéneo y parece haberse reducido con el paso de los años. Durante el reinado de Hasán II, el número de lecciones celebradas cada Ramadán oscilaba entre las 9 y las 18 lecciones; mientras que con la llegada al trono de Mohamed VI, el número de estas ronda las 4-7 lecciones ${ }^{8}$. Este ciclo de conferencias se ha celebrado anualmente a excepción del periodo comprendido entre los años 1967 y 1985 en el que parece que las lecciones se celebraron de manera intermitente (al-Hāššimī al-Balgītīi, 1996: 263-299), así como en el año 2020 en el que fueron canceladas debido a la situación derivada por la pandemia del coronavirus (al-Daḥmānī, 2020).

Aunque se haya tratado con detalle anteriormente, es necesario recordar que todo el ceremonial aquí analizando se desarrolla bajo la presidencia del el soberano marroquí en calidad de Amīr alMu'mininn. Una vez remarcado el rol que desempeña el rey, las Lecciones Hasaníes se desarrollan de la siguiente manera:

Una vez que los asistentes se encuentran ubicados en sus respectivos sitios, el rey entra acompañado de los dos miembros de la familia real siguientes en la línea de sucesión al trono - en el caso de Mohamed VI, su hijo Mawlāy Hasán y su hermano Mawlāy Rašīd. También lo acompañan dos chambelanes que, al entrar el monarca, entonan "Dios bendiga la vida de mi señor", en árabe dialectal (Allāh ybārikf-'umr sīdī). Esta fórmula también es utilizada en otras ceremonias reales como en la bay'a o juramento de lealtad durante la Fiesta del Trono (Fernández Fonfría, 2018: 735). Tras ello, todos los asistentes se sientan en el suelo, así como el rey. El monarca, los miembros de la familia real que lo acompañan y los chambelanes que se colocan detrás del rey - se sientan de cara al púlpito desde el que el ulema va a impartir la lección (al-Ḥāšimī al-Balgîtīi,1996: 167). El hecho de que el monarca se siente en el suelo como el resto de asistentes lo posiciona como primus inter pares al recibir la lección de manera pasiva al igual que el resto de asistentes.

Posteriormente, un recitador sentado a un lado del púlpito salmodia la fórmula de apertura. Esta comienza con una serie de saludos hacia el Profeta, así como varias fórmulas religiosas. Tras ello, recita el siguiente hadiz de Muslim - "Inna așdaq al-ḥadīt kitāb Allāh wa-jayr al-hadī hadī sayydinā Muḥammad, wa-šarra l-umūr muḥdațātuhā wa-kulla muhdața bid'a wa-kulla bid'a ḍalāla wa-kulla dalāla fī-l-nār" ${ }^{\prime \prime}$. A continuación, el recitador pronuncia el título de la lección del día y la aleya

\footnotetext{
${ }^{7}$ Para una lección del año 1988 se ha utilizado el vídeo "Dars ḥasanī fĩ ḥaḍrat al-malik al-Ḥasan al-țānī raḥimahu Allāh li-šayj Mușțafà Binḥhamza mafhūm al-bid'a" (Lección Ḥasaní en presencia del rey Hasán II, descanse en paz, del jeque Mușțafà Binḥhamza Comprensión de la Innovación), Qanāt faḍila al-šayj Mușțafà Binḥhamza (Canal del jeque Mușțafà Binḥhamza), YouTube, 7 de agosto de 2015, disponible https://www.youtube.com/watch?v=FMgRmllsOew\&list=PL7ujmYN8deLhdwvODYFGaMn76sqULgXp6 [consulta: 10 de junio de 2020] y para una lección del año 2017 se ha utilizado el vídeo "Aḥmad al-Tawfĩq: Dawr 'ulamā' al-Magrib fī himāyat al-huwiyya al-wațaniyya" (Aḥmad al-Tawfĩq: el papel de los ulemas marroquíes en la defensa de la identidad nacional), Wizārat al-awqāf wa-l-šu'ūn al-islāmiyya (Ministerio de Habous y Asuntos Islámicos, YouTube, 29 de mayo de 2017, disponible en: https://www.youtube.com/watch?v=nMDy2aBAVxs\&t=224s[consulta: 10 de junio de 2020].

${ }^{8}$ Es muy importante aclarar que no se disponen de datos de los años comprendidos entre 1995-1997. Los datos de años anteriores han sido extraídos de las tablas que se encuentran en (al-Hāššīi al-Balgītīi,1996: 263-299) y (Bū Rakba, 1996: 287-362), mientras que los datos posteriores a 1997 han sido extraídos de cada ciclo de lecciones que ha publicado de manera individual el Ministerio anualmente.

${ }^{9}$ Este hadiz puede ser traducido como: "La palabra más verdadera es el Libro de Dios y la mejor guía es la guía de Muḥammad. Las peores cosas son las que se inventaron recientemente, toda cosa inventada es una innovación (respecto a la religión), cada innovación es una perversión y toda perversión está en el fuego (del infierno)".
} 
coránica o hadiz sobre el que se edifica la lección. Finalmente, el ulema situado en una posición más elevada por la altura del púlpito imparte su lección - que acostumbra a ser leída. A continuación y tras el rezo conjunto de una plegaria $\left(d u^{\prime} \bar{a}^{\prime}\right)$, el rey junto al Ministro de Habous y Asuntos Religiosos saluda al ulema que ha impartido la lección y continúa saludando de manera protocolaria a representantes islámicos que han asistido al acto ${ }^{10}$.

Desde el comienzo de estas lecciones en el año 1963, la lección inaugural no presenta ningún ceremonial particular, salvo que siempre es impartida por el ministro de Habous y Asuntos Islámicos. Puesto que ocupa actualmente Aḥmed al-Tawfĩq y, que hasta el Ramadán de 2001, ocupó 'Abd al-Kabīr Mdagrī al-'Alawī. En cambio, el acto de clausura (al-ijtitām) de estas lecciones presenta unas características particulares al entremezclar el propio ceremonial de las Lecciones Hasaníes con otras prácticas propias del mes de Ramadán. Según las obras consultadas y el visionado de las ceremonias de los últimos 3 años, se aprecia que la clausura de las lecciones ha estado relacionada con las celebraciones religiosas de una de las fechas más señaladas del mes de Ramadán, la Noche del Destino (Laylat al-qadr) ${ }^{11}$.

\footnotetext{
${ }^{10}$ La información se ha extraído de la obra de Ḥaššimī al-Balgītīi de 1996 y de la visualización de las siguientes lecciones: año 2017 “Aḥmad al-Tawfíq: Dawr 'ulamā' al-Magrib fị ḥimāyat al-huwiyya al-wațaniyya" (Aḥmad al-Tawfíq: el papel de los ulemas marroquíes en la defensa de la identidad nacional), Wizārat al-awqāf wa-l-šu'ūn al-islāmiyya (Ministerio de Habous y Asuntos Islámicos, YouTube, 29 de mayo de 2017, disponible en: https://www.youtube.com/watch?v=nMDy2aBAVxs\&t=224s [consulta: 10 de junio de 2020], año 2013 "Dawr al-ïmām fĩ al-muhāfaz̧a șịḥat al-nufūs wa-l-abdān" (El papel de la fe en la preservación de la salud de las almas y los cuerpos), Wizārat al-awqāf wa-l-šu'ūn al-islāmiyya (Ministerio de Habous y Asuntos Islámicos, YouTube, 31 de enero de 2019. Disponible en : https://www.youtube.com/watch?v=jyis6gpHUUc [consulta: 10 de junio de 2020], año 1999-2000 "Aḥsan al-ḥadīt al-brūfisūr 'Abd Allāh al-Ṭayyib fĩ maŷlis malik al-magrib al-durūs al-Ḥasaniyya" (El mejor hadiz del profesor 'Abd Allāh al-Ṭayyib en la asamblea del rey de Marruecos las Lecciones Hasaníes), Alrawnaq sd, 27 de agoto de 2015, disponible en https://www.youtube.com/watch?v=jyUqYaRXCCs\&list=RDjyUqYaRXCCs\&start_radio=1\&t=55 [consulta: 10 de junio de 2020], año 1998 "Min al-durūs al-Ḥasaniyya li-l-imām al-Būțī bi-ḥuḍūr malik al-magrib bi"unwān: maḥabbat Allāh hiyya al- 'ilâŷ al-awḥad" (Una de las Lecciones Hasaníes del imam al-Būțī en presencia del rey de Marruecos titulada: El amor de Dios es el único remedio), Al-imām al-šahīd al-Būțī, YouTube, 21 de junio de 2016, disponible en https://www.youtube.com/watch?v=BAfYU_n7alE [consulta: 10 de junio de 2020] y año 1988 "Dars ḥasanī fị ḥaḍrat al-malik al-Ḥasan al-țānī raḥimahu Allāh li-šayj Mușțafà Binḥhamza mafhūm al-bid'a" (Lección Hasaní en presencia del rey Hasán II, descanse en paz, del jeque Mușțafà Binḥhamza Comprensión de la Innovación), Qanāt faḍīla al-šayj Mușțafà Binḥhamza (Canal del jeque Mușțafà Binḥhamza), YouTube, 7 de agosto de 2015, disponible en: https://www.youtube.com/watch?v=FMgRmllsOew\&list=PL7ujmYN8deLhdwvODYFGaMn76sqULgXp6 [consulta: 10 de junio de 2020].

${ }^{11}$ La Noche del Destino, de acuerdo a la tradición islámica, es particularmente relevante porque se conmemora la noche en la que Muhammad recibió por primera vez una revelación coránica. La información se ha obtenido a partir de Ḥāšimī al-Balgītīi, 1996: 171-174 y de la visualización de la celebración de la clausura del ciclo de conferencias los siguientes años: año 2019 "Amīr al- Mu'minīn yatara"as bi-l-Ribāț ḥaflan dīniyy ${ }^{\text {an }}$ kabīrra iḥyā' li-laylat al-qadr al-mubāraka" (El comendador de los creyentes preside en Rabat una gran fiesta religiosa: las celebraciones de la bendita Noche del Destino), Wizārat al-awqāf wa-l-šu'ūn al-islāmiyya (Ministerio de Habous y Asuntos Islámicos, YouTube, 11 de junio de 2019, disponible en: https://www.youtube.com/watch?v=Jez5tq0b8HY [consulta: 10 de junio de 2020], año 2018 "Amir al- Mu'minīn yatara"as bi-masŷid ḥasan bi-I-Ribāț ḥaflan dīniyy ${ }^{a n}$ kabīran $^{\text {an }}$ iḥyā' li-laylat al-qadr al-mubāraka" (El comendador de los creyentes preside en la mezquita de Hasán en Rabat una gran fiesta religiosa: las celebraciones de la bendita Noche del Destino) Wizārat al-awqāf wa-I-šu'ūn al-islāmiyya (Ministerio de Habous y Asuntos Islámicos, YouTube, 12 je junio de 2018, disponible en: https://www.youtube.com/watch?v=NcD8XOuM34s\&list=PLffkxBSUUPe2IDC0Ace2tY7njZ-MZW7Ai\&index=9 [consulta: 10 de junio de 2020] y año 2017 "Amīr al- Mu'minīn yatara”'as bi-masŷid al-Ḥasan al-țānī bi-Dār al-Bayḍā'

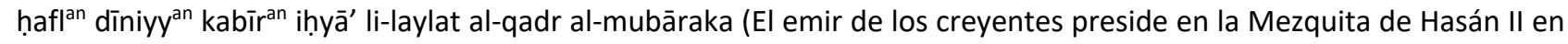
Casablanca una gran fiesta religiosa: las celebraciones de la bendita Noche del Destino), "Wizārat al-awqāf wa-l-šu'ūn
} 
De acuerdo a los vídeo publicados por el Ministerio de Habous y Asuntos islámicos de la celebraciones de los años 2019, 2018 y 2017, este ceremonial se desarrolla de la siguiente manera:

Tras la llegada de la comitiva real, compuesta por el rey Mohamed VI, su hijo Mawlāy Hasán y su hermano Mawlāy Rašĩd, y situarse en la primera línea de fieles, se procede al rezo de la oración ritual del 'išă' y al rezo del tarawīh, oración nocturna propia del mes de Ramadán. A continuación, se procede a la lectura coránica salmodiada por parte de un niño (en el 2019 fue realizada por una niña).

Más relacionado con el ceremonial propio de las Lecciones Hasaníes en sí, uno de los invitados pronuncia la alocución en nombre de los ulemas participantes en el ciclo de Lecciones Hasaníes de ese año. Tras ello, el ulema sentado en el púlpito, imparte su lección. A diferencia del ceremonial antes descrito, en la celebración de clausura el ulema inicia un tașbị̣ (jaculatoria breve repetida de forma ininterrumpida) que es seguido por el resto de asistentes. Finalmente, los asistentes realizan una plegaria $\left(d u^{\prime} \bar{a}^{\prime}\right)$.

Las ceremonias descritas apenas han cambiado a lo largo del tiempo de acuerdo a lo explicado por al-Hāšimī al-Balgītīi en su obra de 1996 y al análisis de las lecciones más recientes. No obstante, se aprecian algunos cambios significativos que permiten especular sobre la percepción de sí mismos de Hasán II y de Mohamed VI. El primero de ellos muestra una actitud más activa y se presenta al mismo tiempo como rey y ulema. En cambio, Mohamed VI mantiene una actitud mucho más pasiva. De esta manera, el actual monarca con su actitud silente se presenta como primus inter pares que aún ostentando un título califal, asiste a este ceremonial como un fiel más y no como un ulema. Entre los cambios que presenta este ceremonial a lo largo del tiempo:

a) Hasán II, a diferencia de Mohamed VI quien toma un rol pasivo, participó impartiendo él mismo algunas lecciones, sobre todo en la Noche del Destino ${ }^{12}, b$ ) otra de las diferencias que se aprecian con el paso de tiempo es que en la época del monarca anterior eran invitados literatos que recitaban casidas poéticas en honor al rey ${ }^{13}$ y c) desde el Ramadán de 2003 una mujer ulema imparte cada año una lección, una medida que puede relacionarse con lo explicado por M. Pérez Mateo en su artículo "Murchidat: renacimiento islámico femenino como control estatal del discurso religioso en Marruecos", en el que se explica cómo el Ministerio de Habous y Asuntos Islámicos a través de la promoción de ciertos programas formativos religiosos como el de murchidat -guias religiosas femeninas- pretende difundir

al-islāmiyya (Ministerio de Habous y Asuntos Islámicos), YouTube, 22 de junio de 2017, disponible en: https://www.youtube.com/watch?v=zy4LyKuY1wc [consulta: 10 de junio de 2020].

${ }^{12}$ Por ejemplo, en al-Ḥāšimī al-Balgītīi,1996: 251-258 recoge una lección impartida por el propio Hasán II en el acto de clausura del ciclo de conferencias de 1991.

${ }^{13}$ Por ejemplo, en al-Ḥāšimī al-Balgītīi,1996: 237-240 se recogen dos casidas poéticas dirigidas a Hasán II de los años 1991 y 1992. También puede verse otro ejemplo de casida poética dirigida al monarca en "al-Malik al-Ḥasan al-țānī raḥimahu Allāh - yuqaddiru al-šu'arā'”' (El rey Hasán segundo, descanse en paz, valora a los poetas), Șāliḥ al-Mānsī, 11 de marzo de 2013, disponible en: https://www.youtube.com/watch?v=xaFPkul_KZ4 [consulta: 10 de junio de 2020]. 
un islam modelado de acuerdo a la estrategia implantada de manera estatal mediante la promoción de figuras religiosas femeninas (Pérez Mateo: 2015).

\section{Participantes en el acto discursivo}

Los participantes en el acto discursivo analizado pueden clasificarse en: los emisores del discurso (actores activos) y los receptores del discurso (actores pasivos). El primer grupo, a su vez, ha de ser dividido en dos: la parte legitimadora, Ministerio e invitados, y la parte legitimada, la institución monárquica. Por tanto, la elección correcta de los participantes, así como el rol determinado que cada actor asume, es determinante para crear el efecto deseado en los receptores del acto discursivo.

En primer lugar, debe quedar claro que, aunque la lección de cada día sea impartida por un ulema, el eje en torno al cual gira toda la ceremonia es la presidencia del rey como Amìr al-Mu'minin (emisor-parte legitimada). Por otro lado, el Ministerio de Habous y Asuntos Islámicos desempeña un papel esencial como organizador de las Lecciones Hasaníes y como productor del discurso islámico institucional (emisor-parte legitimadora). De hecho y como ya se ha mencionado, el propio ministro es quien inaugura con su lección cada año este ciclo de conferencias (al-Ḥāšimī alBalgîtīi,1996: 169). El rol de productor del discurso religioso institucional que desempeña este ministerio se debe en parte a que éste junto a otros ministerios como el de Justicia, Interior, Relaciones Exteriores y Defensa, forman parte de los considerados ministerios de soberanía al ser fijados sus objetivos directamente por el Rey (Ahmed Chaarani, 2004, 381). Lo que permite a los ministerios antes citados remar en la misma dirección y, por tanto, utilizar las Lecciones Hasaníes como una herramienta más para lograr ciertos objetivos, como por ejemplo, la lucha contra el terrorismo ligada al Ministerio de Interior o la estrategia del Ministerio de Relaciones Exteriores basada en la utilización de las relaciones transnacionales de ciertos grupos sufíes como estrategia de soft power en África Occidental (Hernando de Larramendi, 2017: 14-15).

Los invitados en sí constituyen, obviamente, otro de los participantes clave del acto discursivo estudiado (emisor-parte legitimadora). En la relación a lo que se comentaba anteriormente referente a la labor conjunta de los conocidos como ministerios de soberanía, las Lecciones Hasaníes cumplen en cierto modo la función de recepción diplomática. A ellas acuden tanto representantes públicos marroquíes (miembros del gobierno, altos cargos militares o académicos), como delegaciones de otros países seleccionados cuidadosamente por el Ministerio de Habous y Asuntos Islámicos (al-Ḥāšimī al-Balgītīi,1996: 165).

En cuanto a los ulemas participantes, es importante remarcar su heterogeneidad. No solo en cuanto a su procedencia geográfica, sino también de su filiación doctrinal. Un ejemplo de ello es la participación de clérigos chiíes como el caso del libanés Musà al-Șadr, fundador del movimiento Amal, en el ramadán de 1974 o en el año 2006, el ayatolá iraní Muhammad 'Alī al-Tasjirī con una lección titulada "El movimiento de aproximación entre doctrinas. Bases y perspectiva futuras" (alDaḥmānī, 2020)14. Más sorprendente resulta aún la participación en el año 1983 de Yūsuf alQaraḍāwī, un popular clérigo afín a los Hermanos Musulmanes (al-Daḥmānī, 2020 y al-Ḥāšimī alBalgîtīi1996: 279). Por otro lado, bien es cierto que no se tiene constancia oficial del proceso de

\footnotetext{
${ }^{14}$ Aunque en la publicación de al-Daḥmānī, 2020 se indique que Musà al-Ṣadr participó en 1978, en la obra publicada por el Ministerio se indica que participó en 1974 (al-Ḥāšimī al-Balgītīi,1996: 275).
} 
selección de los ulemas participantes, ni de si estos son invitados a hablar de algún tema en particular. En cualquier caso, la variada nómina de invitados internacionales que participan en las Lecciones Hasaníes ayudan a crear una suerte de juego de espejos entre la esfera nacional e internacional que en sí mismo conforma una herramienta de legitimación. El monarca marroquí al invitar a representantes extranjeros en calidad de Amìr al-Mu'minin, dignidad islámica que sobrepasa el ámbito nacional, recibe una legitimidad tanto en clave local como regional al ser reconocido por autoridades islámicas de otros países.

Finalmente, los receptores externos a los que llega este discurso a través de diversos medios constituyen el fin último de este acto discursivo. Dado que el Ministerio pretende llegar al mayor número posible de personas, las Lecciones Hasaníes han sido difundidas por plataformas variadas a lo largo de su historia: televisión, radio, prensa y, más recientemente, canales oficiales en internet como la página del Ministerio o el canal oficial del Ministerio en YouTube. Paralelamente, desde sus comienzos en 1963 se ha desarrollado una labor de recopilación, edición, traducción y publicación de este ciclo de conferencias (Bū Rakba, 1996: 175-176).

\section{Conclusiones}

Después de lo expuesto en este artículo, se puede concluir que la monarquía marroquí utiliza las Lecciones Hasaníes como un instrumento para mantener la hegemonía del discurso religioso marroquí. Como élite en competición por un recurso limitado, la corona ha de utilizar los recursos discursivos a los que tiene acceso de manera exclusiva para seguir manteniendo sus privilegios. Por otro lado, el ceremonial concreto de las Lecciones Hasaníes constituye un objeto de estudio muy útil para investigar de manera detallada cómo la institución monárquica pone en práctica lo anteriormente explicado y cómo esto encuentra una expresión tanto discursiva como semiológica. Toda esta estrategia, a pesar de experimentar ciertas variaciones a lo largo del tiempo, en último término siempre ha hundido y hunde sus raíces en la reinterpretación de las instituciones clásicas y en la relectura del pasado islámico. Por ello, las Lecciones Hasaníes, sirven para analizar de manera efectiva y detallada la utilización de ciertos recursos legitimadores cuyo acceso es exclusivo de la institución monárquica. En este aspecto, el paradigma clásico de la Imārat al-Mu'minīn se presenta como el pilar sobre el que se edifica el resto de recursos legitimadores de base religiosa a los que la monarquía tiene acceso y que utiliza con el fin de mantener la hegemonía del discurso religioso. 
Miguel A. Fernández-Fernández, Al-Durūs al-Hasaniyya...

\section{Referencias}

AL-DĀHMĀNIĪ, Yūsuf (2020): "Al-durūs al-Ḥasaniyya: riŷāl dīn šía yulqinū durūsan amām al-Ḥasan altāāi wa-Muḥammad al-sādis" (Lecciones Ḥasaníes: clérigos chiíes imparten lecciones frente a Hasán II y Mohamed VI), Yabiladi, 23 de marzo de 2020, disponible en: https://www.yabiladi.ma/articles/details/92651/دين-رجال-الحسنية-الدروس-18868

شيعة.html? ga=2.156082939.1948170158.1591802861-1884868047.1591802861[ consulta: 10 de junio de 2020].

AL-Ḥ̂̄ŠIMĪ AL-BALGĪT̄ī, Āsiyya (1996): al-Maŷālis al-'ilmiyya al-șultāniyya 'alà 'ahd al-dawla al'alawiyya al-šarīfa (segundo tomo), Mohammedia, Wizārat al-Awqāf wa-l-Šu'ūn al-Islāmiyya.

BŪ RAKBA, al-Sa'îd, (1996): Dawr al-waqf fĩ I-ḥayāt al-țaqāfiyya bi-l-magrib fì 'ahd al-dawla al'alawiyya (segundo tomo), Mohammedia, Wizārat al-Awqāf wa-I-Šu'ūn al-Islāmiyya.

CASANI HERRANZ, Alfonso (2017): "Islamistas e izquierda en la oposición política marroquí: un análisis de sus relaciones a través del estudio de al-Adl w-al-Ihsan", Revista de Estudios Internacionales Mediterráneos, 23, 1-14. DOI: https://doi.org/10.15366/reim2017.23.001

CHAARANI, Ahmed (2004): La mouvance islamiste au Maroc, Paris, Karthala.

DAADAOUI, Mohamed (2011): Moroccan Monarchy and the Islamist Challenge. Maintaining Makhzen Power, Palgrave Macmillan, Nueva York.

ECO, Umberto (2000): Tratado de Semiótica General, Barcelona, Lumen.

EL-KATIRI, Mohammed (2013): "The institutionalisation of religious affairs: religious reform

in Morocco", The Journal of North African Studies, n o18:1, pp. 53-69. DOI: https://doi.org/10.1080/13629387.2012.712886.

FERNÁNDEZ FONFRÍA, Lidia (2018): “Iconografía y simbolismo: el ceremonial tradicional jerifiano en la revista Da'wat al-Haqq", eHumanisya/IVITRA, no 14, 732-723, disponible en https://www.ehumanista.ucsb.edu/sites/secure.Isit.ucsb.edu.span.d7 eh/files/sitefiles/ivitra/volu me14/E/ehum.ivitra12.fernandezfonfria\%20\%20\%203.pdf [consulta: 10 d ejunio de 2020].

GIIB, H. A. R., "AMĪR AL-MU'MINĪN", en Gibb, H. A. R. et al. (eds.) (1979): The Encyclopaedia of Islam, Leiden, E. J. Brill, vol. 1, pág. 445.

HERNANDO DE LARRAMENDI, Miguel (mayo 2018): "Islam y política exterior: El caso de Marruecos", Revista UNISCI, no 47, pp. 85-104. DOI: http://dx.doi.org/10.31439/UNISCI-4

IZQUIERDO BRICHS, Ferran (ed.) (2009): Poder y regímenes en el mundo árabe contemporáneo. Barcelona, Fundació CIDOB/Bellaterra.

MACÍAS AMORETTI, Juan Antonio (2008): Entre la fe y la razón: los caminos del pensamiento político en Marruecos, Alcalá la Real, Alcalá Grupo Editorial.

MARTÍNEZ NÚNEZ, María Antonia (2006): “El papel del islam en Marruecos: legitimación del poder y activismo político-religioso", en: PÉREZ BELTRÁN, Carmelo (ed.): Sociedad civil, derechos humanos y democracia en Marruecos, Granada: Editorial Universidad de Granada, pp. 149-179 .

PÉREZ BELTRÁN, Carmelo. y MACÍAS AMORETTI, Juan. Antonio. (2017): La construcción histórica de la hegemonía ideológica del PJD en Marruecos: la marcha islámica de 2000 y el debate sobre las 
PÉREZ MATEO, Mariví (diciembre 2015): “Murchidat: renacimiento islámico femenino como control estatal del discurso religioso en Marruecos", Feminismo/s, $\mathrm{n}$ o 26, pp.175-195. DOI: http://dx.doi.org/10.14198/fem.2015.26.09.

TOMÉ ALONSO, Beatriz (enero 2009): “El islam político en Marruecos. Dos estrategias enfrentadas: participación institucional frente a oposición desde Fuera", Revista UNISCI, no 19, pp. 186-205. Disponible en http://www.unisci.es/el-islam-politico-moderado-en-marruecos-dos-estrategiasenfrentadas-participacion-institucional-frente-a-oposicion-desde-fuera/ [consulta: 15 de mayo de 2021].

TOZY, Mohamed (2000): Monarquía e islam político en Marruecos. Barcelona, Ediciones Bellaterra. VAN DIJK, Teun A. (2017): “Análisis crítico del discurso". Revista Austral de Ciencias Sociales, no 30, pp. 203-222. DOI: https://doi.org/10.4206/rev.austral.cienc.soc.2016.n30-10.

\section{Grabaciones de los al-Durūs al-Ḥasaniyya consultadas}

"Aḥmad al-Tawfīq: Dawr 'ulamā' al-Magrib fỉ ḥimāyat al-huwiyya al-wațaniyya" (Aḥmad al-Tawfīq: el papel de los ulemas marroquíes en la defensa de la identidad nacional), Wizārat al-awqāf wa-lšu'ūn al-islāmiyya (Ministerio de Habous y Asuntos Islámicos, YouTube, 29 de mayo de 2017, disponible en: https://www.youtube.com/watch?v=nMDy2aBAVxs\&t=224s [consulta: 10 de junio de 2020].

“Aḥsan al-ḥadīt al-brūfīsūr 'Abd Allāh al-Ṭayyib fī maŷlis malik al-magrib al-durūs al-Ḥasaniyya” (El mejor hadiz del profesor 'Abd Allāh al-Ṭayyib en la asamblea del rey de Marruecos las Lecciones Hasaníes), Alrawnaq sd, 27 de agoto de 2015, disponible en https://www.youtube.com/watch?v=jyUqYaRXCCs\&list=RDjyUqYaRXCCs\&start radio=1\&t=55

[consulta: 10 de junio de 2020].

“al-Malik al-Ḥasan al-țānī raḥimahu Allāh - yuqaddiru al-šu'arā'” (El rey Hasaán segundo, descanse en paz, valora a los poetas), Șālị̣ al-Mānsī, 11 de marzo de 2013, disponible en: https://www.youtube.com/watch?v=xaFPkul_KZ4 [consulta: 10 de junio de 2020].

“Amīr al- Mu'minīn yatara”as bi-masŷid al-Ḥasan al-țānī bi-Dār al-Bayḍā' ḥaflan dīniyy an kabīran iḥyā' li-laylat al-qadr al-mubāraka" (El comendador de los creyentes preside en la mezquita de Hasán II en Casablanca una gran fiesta religiosa: las celebraciones de la bendita Noche del Destino), Wizārat al-awqāf wa-l-šu'ūn al-islāmiyya (Ministerio de Habous y Asuntos Islámicos, YouTube, 22 de junio de 2017, disponible en: https://www.youtube.com/watch?v=zy4LyKuY1wc [consulta: 10 de junio de 2020].

“Amīr al- Mu'minīn yatara"as bi-masŷid Ḥasan bi-l-ribāṭ ḥaflan dīniyyan kabīran iḥyā' li-laylat al-qadr al-mubāraka" (El comendador de los creyentes preside en la mezquita de Hasán en Rabat una gran fiesta religiosa: las celebraciones de la bendita Noche del Destino), Wizārat al-awqāf wa-l-šu'ūn alislāmiyya (Ministerio de Habous y Asuntos Islámicos, YouTube, 12 de junio de 2018, disponible en: https://www.youtube.com/watch?v=NcD8XOuM34s\&list=PLffkxBSUUPe2IDC0Ace2tY7njZMZW7Ai\&index=9 [consulta: 10 de junio de 2020]

“Amīr al- Mu'minīn yatara"as bi-l-ribāț ḥaflan dīniyy an kabīran iḥyā’ li-laylat al-qadr al-mubāraka" (El comendador de los creyentes preside en Rabat una gran fiesta religiosa: las celebraciones de la bendita Noche del Destino), Wizārat al-awqāf wa-l-šu'ūn al-islāmiyya (Ministerio de Habous y Asuntos Islámicos, YouTube, 11 de junio de 2019, disponible en: https://www.youtube.com/watch?v=Jez5tq0b8HY [consulta: 10 de junio de 2020]. 
"Dars ḥasanī fĩ ḥaḍrat al-malik al-Ḥasan al-țānī raḥimahu Allāh li-šayj Mușțafà Binḥhamza mafhūm al-bid'a" (Lección Ḥasaní en presencia del rey Hasán II, descanse en paz, del jeque Mușțafà Binḥhamza Comprensión de la Innovación), Qanāt faḍila al-šayj Mușțafà Binḥhamza (Canal del jeque Mușțafà Binḥhamza), YouTube, 7 de agosto de 2015, disponible en: https://www.youtube.com/watch?v=FMgRmllsOew\&list=PL7ujmYN8deLhdwvODYFGaMn76sqULg Xp6 [consulta: 10 de junio de 2020].

"Dawr al-īmām fĩ al-muḥāfaẓa șiḥhat al-nufūs wa-l-abdān" (El papel de la fe en la preservación de la salud de las almas y los cuerpos), Wizārat al-awqāf wa-l-šu'ūn al-islāmiyya (Ministerio de Habous y Asuntos Islámicos, YouTube, 31 de enero de 2019. Disponible en : https://www.youtube.com/watch?v=jyis6gpHUUc [consulta: 10 de junio de 2020].

"Min al-durūs al-Ḥasaniyya li-l-imām al-Būțī bi-ḥuḍūr malik al-magrib bi-'unwān: mahabbat Allāh hiyya al- 'ilāŷ al-awḥad" (Una de las Lecciones Ḥasaníes del imam al-Būțī en presencia del rey de Marruecos titulada: El amor de Dios es el único remedio), Al-imām al-šahīd al-Būțī, YouTube, 21 de junio de 2016, disponible en https://www.youtube.com/watch?v=BAfYU n7alE [consulta: 10 de junio de 2020] 